\title{
Profiling Signaling Peptides in Single Mammalian Cells Using Mass Spectrometry
}

\author{
Stanislav $\mathrm{S}_{\dot{*}}$ Rubakhin ${ }^{1}$, James D. Churchill $2, \dagger$, William T. Greenough ${ }^{2}$, and Jonathan V. \\ Sweedler ${ }^{1, *}$ \\ 1 Department of Chemistry, University of Illinois, Urbana, IL, 61801 \\ 2 Department of Psychology, and the Beckman Institute, University of Illinois, Urbana, IL, 61801
}

\begin{abstract}
The peptide content of individual mammalian cells is profiled using matrix-assisted laser desorption/ ionization (MALDI) time-of-flight mass spectrometry. Both enzymatic and non-enzymatic procedures, including a glycerol cell stabilization method, are reported for the isolation of individual mammalian cells in a manner compatible with MALDI MS measurements. Guided microdeposition of MALDI matrix allows samples to be created with suitable analyte-to-matrix ratios. More than fifteen peptides are observed in individual rat intermediate pituitary cells. The combination of accurate mass data, expected cleavages by proteolytic enzymes, and post-source decay sequencing allows identification of fourteen of these peptides as pro-opiomelanocortin prohormone-derived molecules. These protocols permit the classification of individual mammalian cells by peptide profile, the elucidation of cell-specific prohormone processing, and the discovery of new signaling peptides on a cell-to-cell basis in a wide variety of mammalian cell types.
\end{abstract}

\section{INTRODUCTION}

The cell is perhaps the most fundamental physiological systems component. Even in the mammalian brain, which contains trillions of cells and demonstrates a high level of redundancy, stimulation of a single neuron can evoke a complete motor action-e.g., whisker movement.

${ }^{1}$ Investigations of functionally connected physiological components at the individual cell level often elucidate mechanisms of entire system function. Reducing sample size from the tissue to the cell level frequently results in a decrease in chemical and morphological complexity, as well as in relative enrichment of unique analytes in the particular cell analyzed.

While a number of approaches are currently available to gather information about single cell biochemistry and in particular, a cell's signaling peptide complement, these methodologies have limitations. Immunohistochemistry, for example, offers unparalleled subcellular localization information and high specificity, but does not reveal more than a handful of other co-localized compounds. Success has also been achieved in the detection, identification, and quantitation of peptides synthesized and released by a single cell using immunoaffinity array technology. ${ }^{2}$ However, cross-reactivity of antibodies to structurally similar substances can be an issue. Single cell mRNA detection and characterization methods ${ }^{3}$ provide spatially resolved expression data but lack information on prohormone processing and post-translational modifications. Capillary-scale separations such as capillary electrophoresis (CE) with laserinduced fluorescence detection allow small, complex samples to be fractionated and the

*CORRESPONDING AUTHOR: Jonathan V. Sweedler, Department of Chemistry, 600 S. Mathews, 64-5, Urbana, IL 61801, jsweedle@uiuc.edu.

${ }^{\dagger}$ Current address: Department of Psychology, St. Louis University, St. Louis, MO 63103 
individual components quantified. ${ }^{4}$ Although the detection limits are excellent, the limited chemical information provided by commonly employed single-channel detectors makes analyte identification time-consuming.

Conversely, mass spectrometry (MS) has proven to be a powerful tool for investigation of the intercellular signaling molecule complement, including neuropeptides, in tissues, cells, and even subcellular organelles. ${ }^{5,6}$ Single cell MS provides insight on neuropeptide processing and cell to cell heterogeneity by allowing a series of fundamental studies on peptidergic signaling in the central nervous system. $5,7-10$ In recent years, the profiling of larger individual molluskan neurons with matrix-assisted laser desorption/ionization (MALDI) MS 11,12 has resulted in the characterization of several hundred novel peptides, many of which have been confirmed as intercellular signaling molecules. ${ }^{7,} 13-16$ Besides mollusks, the neuropeptide content of individual neurons from other invertebrates such as arthropods, including the cockroach, the corn earworm using MS. ${ }^{17-19}$

In contrast to invertebrate neurons, mammalian cells are smaller (e.g., low picoliter to femtoliter volumes), only containing, at most, attomoles of each analyte. Thus, single mammalian cells represent a significant challenge for MS investigation of their peptide complement. Important investigative protocols requiring optimization include sample preparation, cell isolation and manipulation, and MALDI matrix deposition (or, for electrospray ionization measurement, controlled cell lysis in a restricted volume of MS-friendly buffer). Various approaches have been employed to solve the analytical challenges presented by mammalian cells. Bergquist ${ }^{20}$ analyzed PC1 2 cell monolayers grown on stainless steel MALDI sample plates, detecting a number of substances with molecular masses above 4000 $\mathrm{Da}$. Smaller analytes such as serotonin and histamine were detected in single mast cells by Fung and Yeung; 21 an important feature of their work was coupling of flow cytometry to MS. Shimizu et al. ${ }^{22}$ have been developing microcapillary sampling techniques to investigate analytes in mast cells. Remarkable success has been achieved in the examination of hemoglobin in studies demonstrating the feasibility of single erythrocyte MS analysis by downsizing samples to $\sim 10$ blood cells 23 and optimizing detection protocols to allow observation of analyte amounts similar to those present in a single erythrocyte. ${ }^{24}$ As a result of improved sampling and detection techniques, Hofstadler et al. ${ }^{25}$ and Li et al. ${ }^{26}$ have observed hemoglobin-related compounds in single erythrocytes. These exciting developments document the capabilities of MS to characterize the biochemical profiles of single cells. However, to the best of our knowledge, only limited biological information has been generated from research projects targeting individual mammalian cell measurements with MS. Why is this so, given that single cell MS of invertebrate neurons has been used to characterize hundreds of new neuropeptides? Advancing the study of single mammalian cells demands optimized cell sample preparation techniques, improved methods to achieve maximal extraction of analyte from an individual cell, and the ability to transfer the extracted analyte into an optimal volume of MALDI matrix.

Successful development and validation of a new analytical approach depends on selecting the right experimental model. One of the most successful MALDI MS analyses of vertebrate single cells was achieved using melanocytes from the amphibian, Xenopus laevis. ${ }^{27}$ The pituitary has been used to develop techniques for MALDI MS imaging 28 to achieve semiquantitative MALDI MS analysis of the response of a physiological system to a dietary factor, ${ }^{29}$ as well as to investigate the processing of peptide prohormones in different, genetically modified mouse lines. ${ }^{30,31}$ Therefore, we used the endocrine cells of rat pituitary, which synthesize and release a number of signaling molecules derived from the pro-opiomelanocortin (POMC) and cocaine- and amphetamine-regulated transcript (CART) prohormones, 32,33 to establish and validate the MALDI MS approach for profiling single mammalian cells. This approach utilizes new sample preparation procedures and a commercially available MALDI mass spectrometer. 


\section{EXPERIMENTAL SECTION}

\section{Chemicals}

Sigma-Aldrich (St. Louis, MO, USA) was the source for all chemicals, unless stated otherwise.

\section{Sample preparation}

Pituitary were dissected from adult female Long-Evans rats (Harlan, Indianapolis, IN, USA). Because individual cell isolation is a critical step in sample preparation, to improve sample preservation and reduce the time required for cell isolation, the pituitary were immersed in modified Grey's balanced salt solution (mGBSS) containing (in $\mathrm{mM}$ ): $1.5 \mathrm{CaCl}_{2}, 4.9 \mathrm{KCl}, 0.2$ $\mathrm{KH}_{2} \mathrm{PO}_{4}, 11 \mathrm{MgCl}_{2}, 0.3 \mathrm{MgSO}_{4}, 138 \mathrm{NaCl}, 27.7 \mathrm{NaHCO}_{3}, 0.8 \mathrm{Na}_{2} \mathrm{HPO}_{4}, 25 \mathrm{HEPES}$, and 10 glucose, $\mathrm{pH} 7.2$, with $30 \%$ (v/v) glycerol added. The presence of glycerol allows for removal of the extracellular physiological solution and the handling of individual cells without causing lysis or significant dehydration (Fig. 1). Results of our previously reported CE and MS investigations have demonstrated that glycerol treatment does not significantly change the biochemical profiles of neurons. ${ }^{34,} 35$ Small pieces of interior pituitary, containing several hundred cells, were mechanically extracted and placed onto a No. 2 cover glass (Corning, Corning, NY, USA). The cells were mechanically separated on the glass surface using a fine pipette, pulled from 1-mm outer diameter (OD), 0.75-mm inner diameter, thin-walled, singlebarrel standard borosilicate glass tubing (World Precision Instruments, Sarasota, FL, USA) using a horizontal P-80 Flaming/Brown micropipette puller (Sutter Instrument Company, Novato, CA, USA). The pipette was attached to a MHW-3 micromanipulator (Narishige, Tokyo, Japan) to ensure precise, coordinated movements. All micromanipulations were done under visual control with an Axiovert 25 inverted microscope (Carl Zeiss, Thornwood, NY, USA). Images were recorded using a color AxioCam MRc camera (Carl Zeiss) attached to the microscope and interfaced to a personal computer running the MR Grab software package (Carl Zeiss). Individual cells were relocated to a clean, dry glass surface to minimize the amount of extracellular solution.

Pituitary blots were obtained by briefly pressing the entire pituitary held by a forceps onto a MALDI sample plate surface. After removal of the tissue, the MALDI target was covered with adhered cells and tissue residues, and then covered with MALDI matrix.

To perform MS, the MALDI matrix ( $\alpha$-cyano-4-hydroxycinnamic acid saturated in a 1:1 mixture of acetonitrile: $0.1 \%(\mathrm{v} / \mathrm{v})$ aqueous trifluoroacetic acid) was introduced onto the cells via a $\sim 5-\mu \mathrm{m}$ OD glass micropipette (Fig. 1), manufactured with a PP-83 vertical puller (Narishige). During matrix application, the positive pressure inside the micropipette was maintained using an IM-6 microinjector (Narishige). Utilizing this approach, the matrix added to cover the cell spreads out to a spot measuring only $\sim 50 \mu \mathrm{m}$-about the size of the focused laser illumination in our MALDI mass spectrometer. By reducing the volume of solution and the matrix spot size, successful single-cell measurements become feasible. Preparation of each pituitary cell for MS analysis took about 5-10 min. Mass spectra were acquired from samples localized on glass surfaces mounted on regular MALDI sample plates secured with Scotch tape.

For individual hippocampal neuron isolation, $\sim 400-\mu \mathrm{m}$-thick adult female Long-Evans rat coronal brain sections were incubated at $36^{\circ} \mathrm{C}$ for $\sim 2 \mathrm{~h}$ in oxygenated AmGBSS-mGBSS supplemented with 100 units $/ \mathrm{mL}$ penicillin $\mathrm{G}, 100 \mu \mathrm{g} / \mathrm{mL}$ streptomycin, and $100 \mu \mathrm{g} / \mathrm{mL}$ gentamicin, containing 1\% of Liberase Blendzyme 3 (Roche Molecular Systems, Alameda, CA, USA). Neurons were triturated mechanically by repeated pushes of isolated hippocampal area in and out of a Pasteur pipette and cultured for 15-30 min in AmGBSS on cover glass 
pretreated with $1 \%$ polylysine. The neuronal cultures were briefly washed with $30 \%$ glycerol/ AmGBSS solution before MALDI matrix application, performed as described above.

In experiments where entire regions of the brain were profiled, the HM550 cryostat (RichardAllan Scientific, Kalamazoo, MI, USA) was used to cut $5-\mu \mathrm{m}$ sections from quickly frozen, untreated rat brains; these sections were deposited onto a cover glass. Using the standard dried droplet method, $1 \mu \mathrm{l}$ of MALDI matrix solution (10 mg $\alpha$-cyano-4-hydroxycinnamic acid dissolved in $500 \mu \mathrm{l}$ water, $500 \mu \mathrm{l}$ acetonitrile) was applied to the brain sections.

\section{Mass spectrometry}

MALDI mass spectra were acquired with a commercially available time-of-flight (TOF) mass spectrometer, the Voyager-DE ${ }^{\mathrm{TM}}$ STR BioSpectrometry Workstation (Applied Biosystems, Foster City, CA, USA). Instrument settings were optimized for maximal sensitivity-linear mode, guide wire $0.2 \%$, accelerating voltage $25 \mathrm{kV}$, grid voltage $93 \%$. External calibration of the mass spectra used five peptides [bradykinin (1-6), angiotensin I, adrenocorticotropic hormone (18-39), adrenocorticotropic hormone (7-38), bovine insulin] covering the mass range from 600 to $6000 \mathrm{Da}$. Standards bracketing the peaks of interest were used for mass calibrations to allow accurate peptide molecular mass determination. Mass measurement accuracy was dependent on signal quality and intensity, reaching $30 \mathrm{ppm}$. No peptides were detected in the liquid surrounding the individual cells or at regions of the glass coverslip where cells had been removed, indicating the successful deposition and transfer of the cells without cell lysis. Experimental results were compared with a database of rat signaling peptides created using precursor sequence information obtained from the SWISS-PROT Protein Sequence Database via the SRS6 search engine (http://srs6.ebi.ac.uk/) maintained by the European Bioinformatics Institute, and from literature reports on rat peptides.

\section{RESULTS AND DISCUSSION}

\section{Sample preparation}

MALDI MS investigation of a cell's peptide complement requires application of a small volume of MALDI matrix solution onto the cell. This step allows extraction and incorporation of the peptides into a MALDI matrix without excessive dilution. Two approaches have been used to meet these requirements.

In the first, MALDI matrix solution is deposited on top of the cells while still within the tissue slice, or even in the organ. As result of this treatment, analytes are extracted from the slice and incorporated in MALDI matrix crystals, often allowing the acquisition of MS images of peptides and proteins with nearly single-cell spatial resolution. ${ }^{34,} 36-38$ Unfortunately, cell identification after these manipulations can be problematic. Additionally, the use of matrix application protocols that optimize analyte extraction are apt to reduce spatial information, primarily due to analyte migration. This analyte redistribution tends to be most severe when working with neuropeptides and other smaller hydrophilic molecules. Otherwise, methods can be optimized that preserve analyte localizations but reduce analyte detectability.

In the second approach, individual cells (or cellular clusters) are physically isolated from the tissue. In this case, there is no problem with analyte redistribution so that MALDI MS detection can be optimized. There are multiple techniques for isolating single cells from tissues, including laser capture microdissection, 39,40 which allows automatic sample dissection but requires the use of thin tissue sections. Working with the invertebrate nervous system, we have found that one of the best ways to prepare single cells for MALDI MS analysis is by mechanical isolation of a neuron from a cluster. First, we pretreat the neurons with enzymes to reduce the strength of intercellular contacts. Application of a similar approach to mammalian brain and 
pituitary tissues in our preliminary experiments resulted in the dissociation of tissues into individual cells. However, after sample preparation that included cell micromanipulation to a clean, dry spot on a cover glass, extracellular solution removal, and MALDI matrix application, the peptide signals were almost non-detectable (not shown).

This lack of signal may be due either to leakage of the peptides out of the cell during the sample preparation process, or by the sample having dried completely. To prevent or reduce drying, thereby increasing the cell's mechanical stability, we added glycerol to the extracellular environment during sample preparation. As a result, the isolation of single pituitary cells is possible, even without enzymatic treatment (Fig. $1 \mathrm{~A}-\mathrm{C}$ ). After immersion in a $30 \%$ glycerol solution, cells exhibit high mechanical stability and low adhesion to the glass surface. Both parameters aid the ability to pick specific cells from a spot containing multiple cells and in micropositioning the cell onto a new spot where MALDI matrix can be applied (Fig. 1D). When glycerol is used, it is important to reduce the volume of glycerol-treated hydrated tissue introduced into the mass spectrometer because the excess moisture increases the time it takes for the system to pump-vacuum down to operational levels. Thus, transfer of cells to a clean, dry glass slide is essential.

\section{Mammalian single cell MALDI MS}

Due to the high peptide content in comparison to most other similarly-sized cells, and a welldocumented biochemistry, pituitary cells represent a useful model for establishing and optimizing new approaches for single cell MALDI MS profiling of the peptide complement in biological tissues. For larger samples, sample preparation can be surprisingly simple. Even a tissue blot of rat pituitary placed onto the MALDI sample plate produces excellent MS signals, with several recognizable peptides observed (Fig. 1E). However, the coexistence of Argvasopressin and diacetylated $\alpha$-MSH in the same mass spectrum indicates that peptides originating from different cells have been mixed.

When a single pituitary cell is isolated and prepared for MALDI MS, surprisingly high numbers of peptides are detected (Fig. 1F). On average, 10 peptides, including known and putative signaling peptides, are observed in each cell (see Supporting Information, Table S1, online). Individual pituitary cells have a reproducible profile of molecules, with 14 of them matching by mass to peptides encoded by POMC prohormone, including $\alpha$-MSH and $\beta$-endorphin (Fig. $1 \mathrm{~F}, \mathrm{G})$. Importantly, $\beta$-endorphin and its derivatives have been assigned based on molecular mass and the reported sequence of the POMC prohormone. These assignments are only possible when alanine occupies residue 26 of the POMC prohormone. This fact is confirmed by multiple biochemical, molecular, and mass spectrometric investigations ${ }^{41-44}$ (see also ENTREZ reports NP_647542, AAH58443, and AAM43934). While valine was suggested for this residue $^{45}$ (ENTREZ P01194), it was not confirmed in later studies. No Arg-vasopressin is detected in these samples. One peak in the mass spectra of individual pituitary cells can be assigned as a putative CART peptide by mass. In some cases, a peptide matching by mass to a physiologically active substance, CART (55-102), ${ }^{46}$ is also detected in pituitary cell samples (Supporting Information, Figure S1, online). No molecules originating from erythrocytes are evident in these samples, indicating the high quality of cell isolation and transfer, as such signals are commonly observed in tissue blots and other mass spectra from multiple-cell specimens. These observations complement our experience with invertebrate cells, where the reduction of sample size to the single cell level led to the discovery of new peptides that were otherwise obscured by much stronger signals arising from the more common masses found in larger samples.

Sampling large numbers of similar cells and assaying their homogenate allows one to determine peptides present in these cells. Furthermore, knowledge of cell-specific peptides is important to understanding the functioning of a single cell in a group of otherwise indistinguishable cells. 
However, as the heterogeneity of the sample increases, the benefits from working with a tissue extract decrease. Stated otherwise, if only a small population of cells in a sample have a particular peptide, then combining additional cells devoid of the peptide will complicate detection and identification - the volume of the extra tissue dilutes these particular peptides while introducing potentially interfering species. As an example, if a brain region contains a peptide present in only $0.1 \%$ of the cells in a region, then mixing of analytes from all of the cells dilutes the compound 1000-fold while concentration of the analytes common to all cells remains the same. As a result of this scenario, the demand on the dynamic range of the detection system is elevated significantly.

\section{Peptide identification}

The next challenge for single cell profiling is the identification of the compounds found within the cells. Furthermore, the small amounts of peptides synthesized in individual mammalian cells limit the approaches that can be applied for analyte identification. One approach uses either the measured molecular masses from a single cell experiment for MS-guided purification or enrichment of the unknowns from larger tissue samples, followed by the sequencing of the peptide using methods such as tandem MS. Here, we utilized post-source decay (PSD) ${ }^{47}$ to sequence several peptides having the highest signal intensity in pituitary blots. Figure 2 shows the formation of sequence-specific $b$ - and y-ions, along with internal fragment ions, confirming our assignment of the diacetylated $\alpha-\mathrm{MSH}$ and joining peptide (1-18). Amino acid composition in the form of immonium ions is also obtained. Together, these data allow the unambiguous confirmation of these two peptide assignments.

A second approach to analyte identification is based on the molecular mass measurements and knowledge of prohormone expression in a particular tissue. It is generally accepted in the proteomics field that the masses of individual peptides, formed as result of the enzymatic digestion of a parent protein, can be used as a mass fingerprint for that particular protein. 48 Within individual endocrine cells, typically only a few prohormones are processed by wellcharacterized enzymes. Additionally, a significant amount of information on the processing enzymes that convert a prohormone into mature peptides are available online. ${ }^{49}, 50 \mathrm{Using}$ binary logistic models trained on phyla-specific neuropeptide processing datasets, the expected peptide products can be determined using the web-based tool, NeuroPred (http://neuroproteomics.scs.uiuc.edu/neuropred.html). ${ }^{51-53}$ Comparisons of available information with the results of our single cell MS investigations has permitted tentative identification of an additional 18 peptides (Fig. 2C and Table S1). It is not surprising that 14 of the peptides observed in a single pituitary cell are products of $\mathrm{POMC}$ prohormone processing and that one matches the CART peptide. Both prohormones have been shown to be synthesized in pituitary $28,31,54$ where they are processed into sets of physiologically active peptides.

Stated another way, with 14 peptides matching the expected POMC prohormone products, we maintain high confidence in our POMC-processing assignments.

\section{Towards mammalian neuron MS profiling}

Numerous cells in the mammalian brain present a more difficult target for single cell MS peptide profiling than pituitary cells. Many brain areas may contain lower amounts of peptides, exhibit a more complex biochemistry, or have a lower mechanical stability of cells, thus making sample isolation difficult. Also, dendritic and axonal processes of neurons are hopelessly intertwined with processes of other cells. Simple application of MALDI matrix onto a brain slice typically results in the generation of mass spectra dominated by multiple larger peptides and protein signals (Fig. 3A) with almost no detectable neuropeptides. As one example, almost all mass spectra acquired from different brain regions treated in such a manner have a thymosin$\beta 4$ peak $(4965 \mathrm{~m} / \mathrm{z})$ as one of the dominant features. Thymosin- $\beta 4$ is an actin-binding protein, functionally linked to neurite outgrowth and immunoregulation, and has been observed by 
other researchers investigating brain sections with MS. 55 The higher mechanical stability of mammalian brain tissue makes direct isolation of single neurons, or small groups of cells, difficult. Enzymatic treatment is often used to reduce the strength of intercellular contacts.

In our experiments, brain regions treated with liberase, followed by application of shear force, dissociated into single cells and small cellular clusters. Again, glycerol was added to stabilize the isolated cells. MALDI MS analysis of the small cellular clusters uncovered a different set of peptides (Fig. 3B) as compared to the brain slice profiles. For example, the absence of the thymosin- $\beta 4$ signal in the mass spectrum appears to indicate that not all cells, or regions of cells such as cell bodies, have a high concentration of thymosin- $\beta 4$. These observations provide the opportunity to investigate the cell-specific peptide complement without interference from more common compounds. Despite significant success in peptide detection, identification of the specific source of the observed signals is difficult because neurons and glia are nearly indistinguishable in the preparations used in these experiments. Further investigation will help to determine molecular markers specific to neurons and glia that can be detected by MALDI MS. Additionally, molecular biology-assisted fluorescent labeling of neurons can be used for visual identification of these two major cell types. In general, joint use of molecular biology approaches and MALDI MS promises to uncover many novel peptides in the nervous system.

\section{CONCLUSIONS}

Single cell MALDI MS is a powerful tool for investigation of the peptide complement in various physiological systems. Due to the increasing sensitivity, resolving power, and high throughput of contemporary, state-of-the-art mass spectrometers, successful mammalian peptidomic analysis using this technique is increasingly more reliant upon optimal single cell sample preparation, which unfortunately can also prove to be a limiting step. Therefore, new single cell isolation approaches like the one described in this work will play an important role in advancing single cell MALDI MS. We expect that sample isolation enhancements, such as laser capture microdissection and other cell-manipulation methods, will lead to automation of the sampling process, thereby allowing neuronal populations to be characterized on the single cell and even subcellular level. In addition, improved peptide identification can be expected by introducing a peptide separation and concentration technique (e.g., CE) before mass analysis. By continuing to advance approaches that permit one to observe and measure complex peptide complements from individual mammalian cells, including neurons, the ability to follow cell-specific changes of the peptidome due to aging, experience, disease, or even exposure to drugs, becomes feasible.

\section{Supplementary Material}

Refer to Web version on PubMed Central for supplementary material.

\section{Acknowledgements}

This material is based on work supported by the National Institutes of Health under Awards No. P30 DA018310, to the UIUC Neuroproteomics Center on Cell to Cell Signaling, and DA14879 (J.V.S.); the National Science Foundation under Award No. CHE-05-26692 (J.V.S.); and the National Institutes of Health under Award No. AG10154 (W.T.G.).

\section{References}

1. Brecht M, Schneider M, Sakmann B, Margrie TW. Nature 2004;427:704-710. [PubMed: 14973477]

2. Phillips TM. J Biochem Biophys Methods 2001;49:253-262. [PubMed: 11694283]

3. Hinkle D, Glanzer J, Sarabi A, Pajunen T, Zielinski J, Belt B, Miyashiro K, McIntosh T, Eberwine J. Prog Neurobiol 2004;72:129-142. [PubMed: 15063529]

4. Dovichi NJ, Hu S. Curr Opin Chem Biol 2003;7:603-608. [PubMed: 14580565] 
5. Li L, Garden RW, Sweedler JV. Trends Biotechnol 2000;18:151-160. [PubMed: 10740261]

6. Rubakhin SS, Garden RW, Fuller RR, Sweedler JV. Nat Biotechnol 2000;18:172-175. [PubMed: 10657123]

7. Jimenez CR, van Veelen PA, Li KW, Wildering WC, Geraerts WP, Tjaden UR, van der Greef J. J Neurochem 1994;62:404-407. [PubMed: 8263544]

8. Li L, Romanova EV, Rubakhi SS, Alexeeva V, Weiss KR, Vilim FS, Sweedler JV. Anal Chem 2000;72:3867-3874. [PubMed: 10959975]

9. Garden RW, Shippy SA, Li L, Moroz TP, Sweedler JV. Proc Natl Acad Sci USA 1998;95:3972-3977. [PubMed: 9520477]

10. Garden RW, Moroz TP, Gleeson JM, Floyd PD, Li L, Rubakhin SS, Sweedler JV. J Neurochem 1999;72:676-681. [PubMed: 9930740]

11. Karas M, Hillenkamp F. Anal Chem 1988;60:2299-2301. [PubMed: 3239801]

12. Tanaka K, Waki H, Ido Y, Akita S, Yoshida Y, Yoshida T. Rapid Comm Mass Spectrom 1988;2:151153.

13. Perry SJ, Dobbins AC, Schofield MG, Piper MR, Benjamin PR. Eur J Neurosci 1999;11:655-662. [PubMed: 10051766]

14. Worster BM, Yeoman MS, Benjamin PR. Eur J Neurosci 1998;10:3498-3507. [PubMed: 9824463]

15. Hummon AB, Amare A, Sweedler JV. Mass Spectrom Rev 2006;25:77-98. [PubMed: 15937922]

16. Jimenez CR, Spijker S, de Schipper S, Lodder JC, Janse CK, Geraerts WPM, van Minnen J, Syed NI, Burlingame AL, Smit AB, Li K. J Neurosci 2006;26:518-529. [PubMed: 16407549]

17. Redeker V, Toullec JY, Vinh J, Rossier J, Soyez D. Anal Chem 1998;70:1805-1811. [PubMed: 9599581]

18. Ma PWK, Garden RW, Niermann JT, O'Connor M, Sweedler JV, Roelofs WL. J Insect Physiol 2000;46:221-230. [PubMed: 12770226]

19. Neupert S, Predel R. Biochem Biophys Res Commun 2005;327:640-645. [PubMed: 15649394]

20. Bergquist J. Chromatographia Supplement I 1999;49:S41-S48.

21. Fung EN, Yeung ES. Anal Chem 1998;70:3206-3212. [PubMed: 11013722]

22. Shimizu M, Ojima N, Ohnishi H, Shingaki T, Hirakawa Y, Masujima T. Anal Sci 2003;19:49-53. [PubMed: 12558023]

23. Hofstadler SA, Swanek FD, Gale DC, Ewing AG, Smith RD. Anal Chem 1995;67:1477-1480. [PubMed: 7741217]

24. Valaskovic GA, Kelleher NL, McLafferty FW. Science 1996;273:1199-1202. [PubMed: 8703047]

25. Hofstadler SA, Severs JC, Smith RD, Swanek FD, Ewing AG. Rapid Comm Mass Spectrom 1996;10:919-922.

26. Li L, Golding RE, Whittal RM. J Amer Chem Soc 1996;118:11662-11663.

27. Vazquez-Martinez RM, Malagon MM, van Strien FJ, Jespersen S, van der Greef J, Roubos EW, Gracia-Navarro F. Life Sci 1999;64:923-930. [PubMed: 10201641]

28. Caprioli RM, Farmer TB, Gile J. Anal Chem 1997;69:4751-4760. [PubMed: 9406525]

29. Jimenez CR, Li KW, Dreisewerd K, Mansvelder HD, Brussaard AB, Reinhold BB, Van der Schors RC, Karas M, Hillenkamp F, Burbach JP, Costello CE, Geraerts WP. Proc Natl Acad Sci USA 1997;94:9481-9486. [PubMed: 9256508]

30. Che FY, Biswas R, Fricker LD. J Mass Spectrom 2005;40:227-237. [PubMed: 15706630]

31. Che FY, Fricker LD. J Mass Spectrom 2005;40:238-249. [PubMed: 15706629]

32. Koylu EO, Couceyro PR, Lambert PD, Ling NC, DeSouza EB, Kuhar MJ. J Neuroendocrinol 1997;9:823-833. [PubMed: 9419833]

33. Raffin-Sanson ML, de Keyzer Y, Bertagna X. Eur J Endocrinol 2003;149:79-90. [PubMed: 12887283]

34. Rubakhin SS, Greenough WT, Sweedler JV. Anal Chem 2003;75:5374-5380. [PubMed: 14710814]

35. Miao H, Rubakhin SS, Sweedler JV. Anal Chem 2005;77:7190-7194. [PubMed: 16285665]

36. Jurchen JC, Rubakhin SS, Sweedler JV. J Am Soc Mass Spectrom 2005;16:1654-1659. [PubMed: 16095912] 
37. Rubakhin SS, Jurchen JC, Monroe EB, Sweedler JV. Drug Discov Today 2005;10:823-837. [PubMed: 15970265]

38. Chaurand P, Schwartz SA, Caprioli RM. Curr Opin Chem Biol 2002;6:676-681. [PubMed: 12413553]

39. Xu BJ, Caprioli RM, Sanders ME, Jensen RA. J Am Soc Mass Spectrom 2002;13:1292-1297. [PubMed: 12443019]

40. Mouledous L, Hunt S, Harcourt R, Harry J, Williams KL, Gutstein HB. Proteomics 2003;3:610-615. [PubMed: 12748941]

41. Bennett HP, Browne CA, Solomon S. Anal Biochem 1983;128:121-129. [PubMed: 6846789]

42. Drouin J, Chamberland M, Charron J, Jeannotte L, Nemer M. FEBS Lett 1985;193:54-58. [PubMed: 2998878]

43. Faull KF, Feistner GJ, Conklin K, Roepstorff P, Andrews PC. Neuropeptides 1998;32:339-349. [PubMed: 10102679]

44. Grigoriants OO, Desiderio DM. Int J Pept Protein Res 1996;47:123-130. [PubMed: 8907509]

45. Drouin J, Goodman HM. Nature 1980;288:610-613. [PubMed: 6255341]

46. Murphy KG. Brief Funct Genomic Proteomic 2005;4:95-111. [PubMed: 16102267]

47. Spengler B. J Mass Spectrom 1997;32:1019-1036.

48. Thiede B, Hohenwarter W, Krah A, Mattow J, Schmid M, Schmidt F, Jungblut PR. Methods 2005;35:237-247. [PubMed: 15722220]

49. http://www.expasy.org/cgi-bin/lists?dbxref.txt.

50. http://www.ornl.gov/sci/techresources/Human_Genome/links.shtml.

51. Amare A, Hummon AB, Southey BS, Zimmerman TA, Rodriguez-Zas SL, Sweedler JV. J Proteome Res 2006;5:1162-1167. [PubMed: 16674105]

52. Hummon AB, Hummon NP, Corbin RW, Li L, Vilim FS, Weiss KR, Sweedler JV. J Proteome Res 2003;2:650-656. [PubMed: 14692459]

53. Southey BR, Rodriguez-Zas SL, Sweedler JV. Peptides 2006;27:1087-1098. [PubMed: 16494967]

54. Smith SM, Vaughan JM, Donaldson CJ, Fernandez RE, Li C, Chen A, Vale WW. Endocrinology 2005:1213-1223. [PubMed: 16339196]

55. Stoeckli M, Chaurand P, Hallahan DE, Caprioli RM. Nat Med 2001;7:493-496. [PubMed: 11283679] 

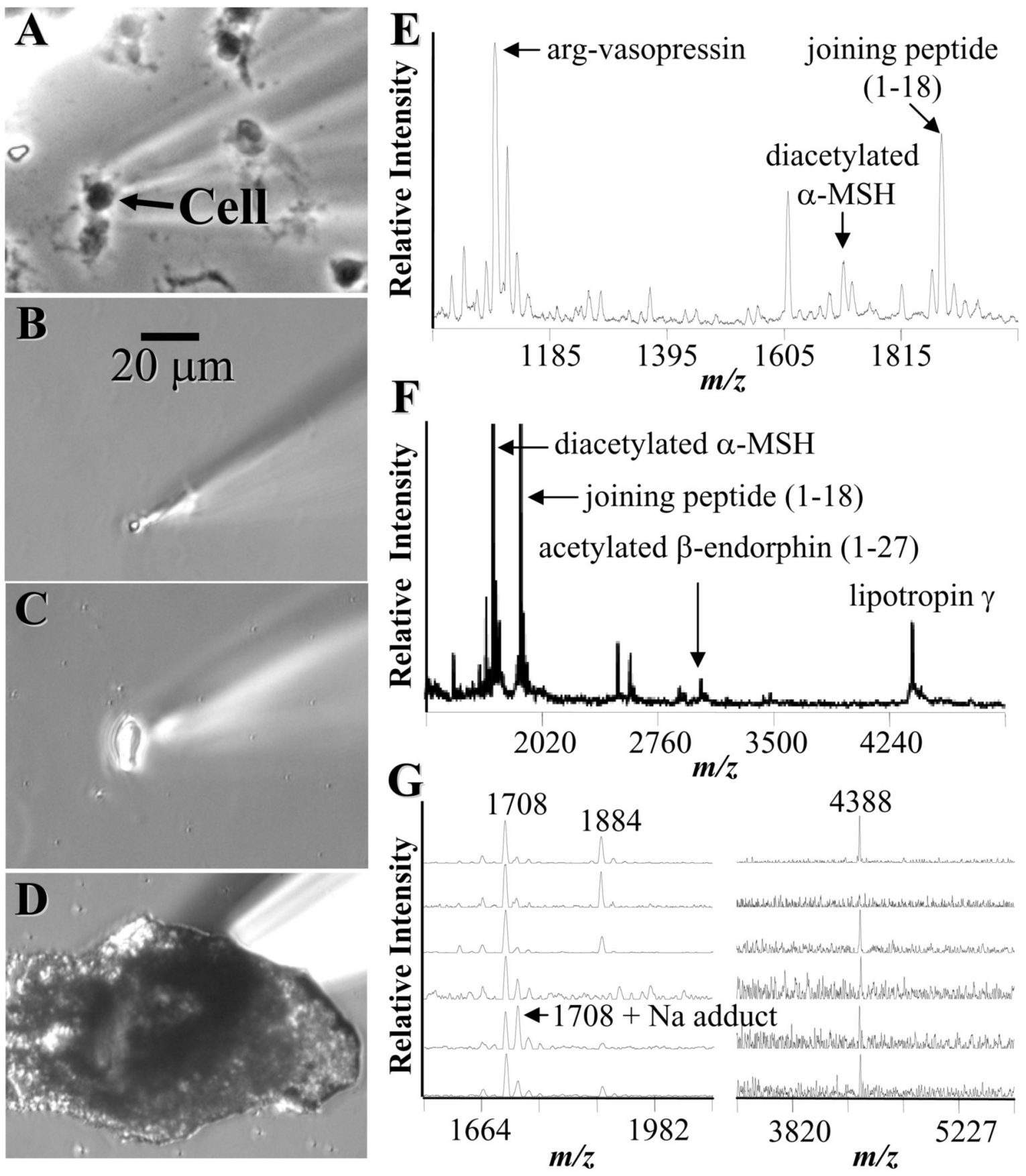

Figure 1.

Mass spectrometric profiling of a single mammalian cell and single pituitary cell sample preparation. (A) Attaching the cell to the glass micropipette. (B) Transfer and (C) deposition of the cell onto a clean glass surface. (D) Application of MALDI matrix to the spot containing the cell. (E) Representative mass spectrum of a pituitary blot. (F) Representative mass spectrum of a single pituitary cell. Not all peaks are labeled. The most intense peaks are truncated to improve visibility of smaller peaks. (G) Portions of the mass spectra obtained from six different, isolated pituitary cells. The $1708 \mathrm{~m} / \mathrm{z}$ and $1884 \mathrm{~m} / \mathrm{z}$ peaks correspond to diacetylated $\alpha-\mathrm{MSH}$ and joining peptide (1-18). Typically 200-300 laser shots are averaged for each mass spectrum; no more than 1-2 mass spectra could be obtained from a particular single cell sample. 


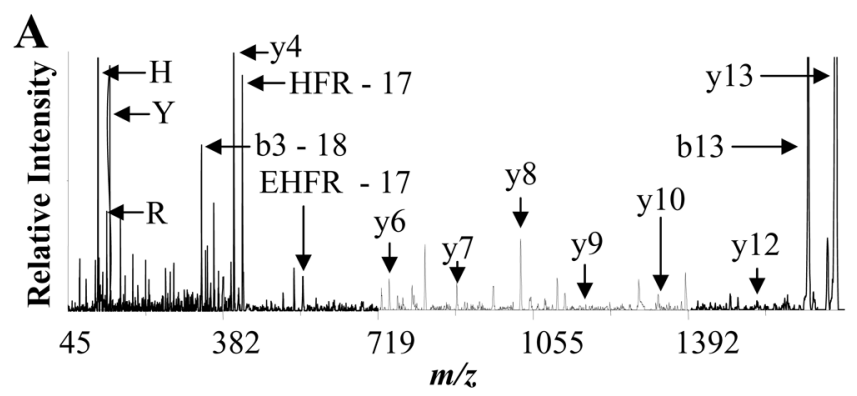

C POMC prohormone

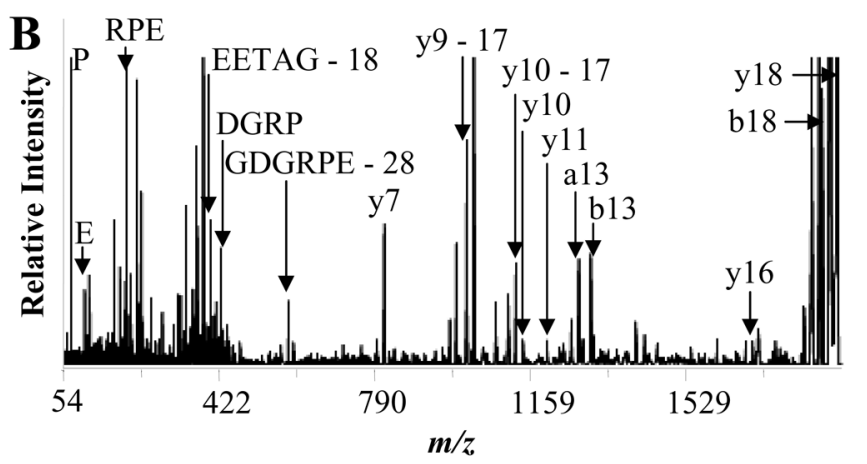

lipotropin $\gamma-\ldots$

$\beta$-endorphin

acetylated $\beta$-endorphin

acetylated $\beta$-endorphin (1-27)

acetylated $\beta$-endorphin (1-26)

NPP (52-74)

$\alpha-\mathrm{MSH}$

acetylated $\alpha-\mathrm{MSH}$

diacetylated $\alpha$-MSH--..-.- $\square$

diacetylated $\alpha$-MSH (3-13)-

joining peptide (1-18) -

$\gamma$-MSH -...-.--

Figure 2.

Peptide identification. PSD analysis of a pituitary blot confirms the identity of the $1708 \mathrm{~m} / \mathrm{z}$ peak as (A) diacetylated $\alpha-\mathrm{MSH}$, and (B) the $1884 \mathrm{~m} / \mathrm{z}$ peak as joining peptide (1-18). The ytype and immonium fragment ions are labeled. Other ion types are present but are not labeled unless they are of particular structural significance. (C) Schematic summary of POMCprohormone processing with the individual lines indicating that a peptide of the appropriate mass is detected from a particular region of the prohormone; this schematic is based on a single pituitary cell spectra, illustrating the excellent prohormone coverage. 


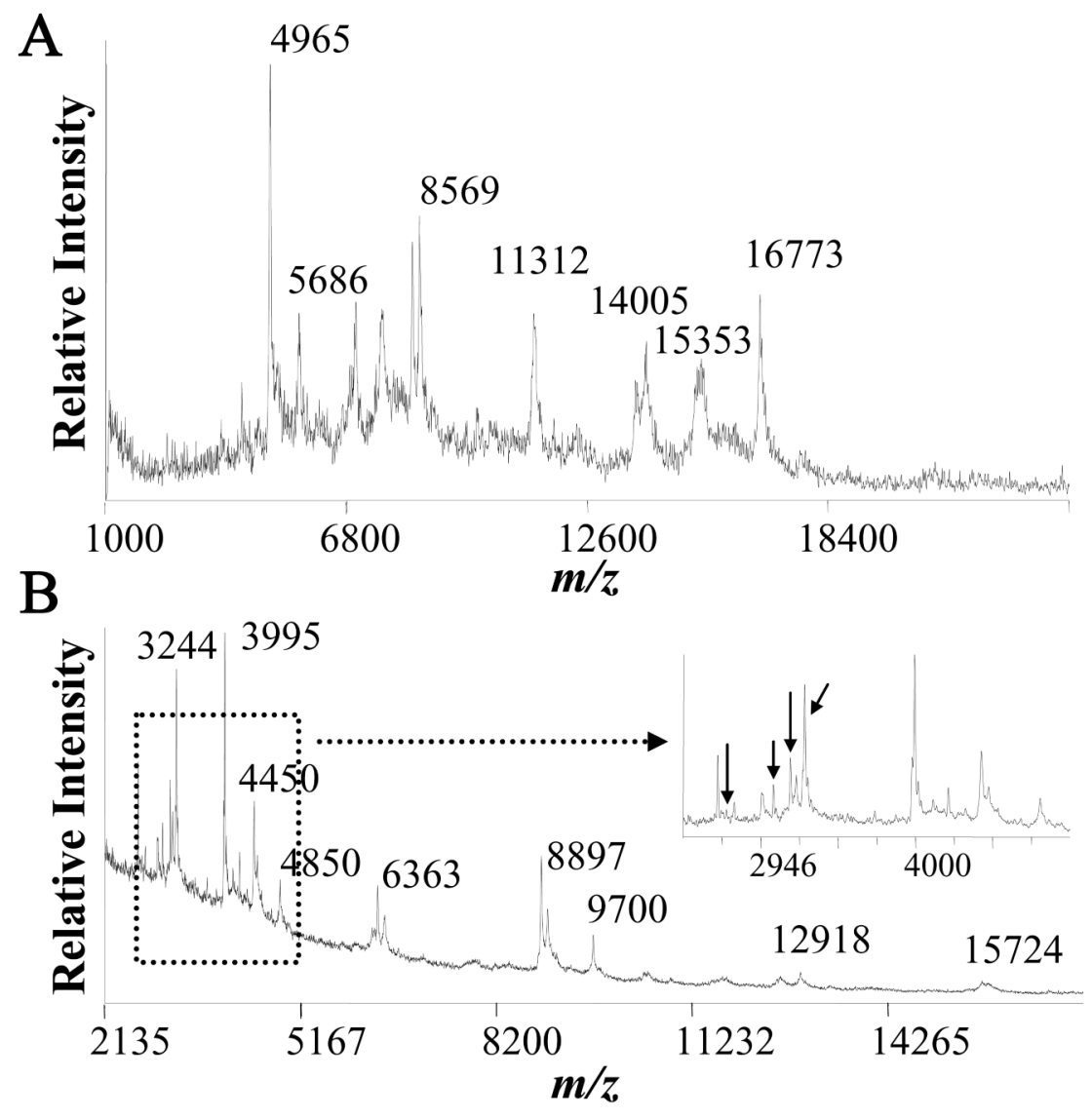

Figure 3.

MALDI-TOF MS peptide profiling of brain sections and isolated neurons. (A) The mass spectrum obtained from a single $\sim 200-\mu \mathrm{m}$ spot located on the surface of a $10-\mu \mathrm{m}$-thick brain slice. (B) The mass spectrum was acquired from group of five enzymatically isolated hippocampal neurons, showing a number of strong, putative neuropeptide signals. 